\title{
Self-service Systems Performance Evaluation and Improvement Model
}

\author{
Darius Dilijonas and Virgilijus Sakalauskas \\ Department of Informatics, Vilnius University, Muitines 8, 44280 Kaunas, Lithuania \\ \{virgilijus.sakalauskas, darius.dilijonas\}@khf.vu.lt
}

\begin{abstract}
The paper analyses the topic of service system productivity and profitability. Main focus of the research is self-service area, namely, the increase of ATM network productivity. Paper presents performance evaluation of self-service systems and improvement model for its increasing profitability. This model combines internal and external quality criteria and provides detailed understanding of the main components of productivity evaluation and methods. Using the model it is possible to create evaluation and improvement tools for increasing productivity of self-service systems. Experimental result shows that using the developed productivity model, ANN method and optimization procedure, productivity of ATM cash management could be increased by approximately 33 percent.
\end{abstract}

Keywords: Self-service, ATM, productivity, profitability, ANN.

\section{Introduction}

Globalization and market liberalization imply changes in basic economic understanding. Organizations begin to realize that the essential issue is not just profit maximization but profit maximization by increasing consumers' satisfaction with the provided services. At present, not just the delivery of services is important; more attention is given to the way of providing the services. Development of information technologies significantly impacts the render of services and the entire sector of services. Consumers now have more information and better understanding of any service, therefore, the competition between service providers is determined by quality, and quality determines profitability [1]. Gartner [2] notices, that there have been major changes in the service sector. Traders are beginning to realize that technologies may have critical importance for the increase of profit and operational efficiency.

The paper analyses the topic of service system productivity and profitability. The work focuses on self-service area, namely, the increase of ATM network productivity. The profitability of electronic service systems depends on their productivity and quality of the services provided. It is possible to ensure the productivity of service systems by efficient planning and by improving delivery process. In order to avoid affecting delivery process in service systems, it is very important to make timely decisions. It is impossible to store services like goods; therefore, inadequate decisions are related to the direct loss of income and quality decrease. 
The productivity of electronic services may be ensured by implementing advanced real-time decision management systems and by changing the realization of service system quality from traditional to predictive. The quality of such systems is ensured by predicting service system behavior. Multi-agent technologies are used for data collection from distributed service points [3]. Intelligent agents evaluate the demand of service system resources according to the collected data, and plan the work to have sufficient resources for services and to maintain high quality and maximum system availability. Applying intelligent systems of resource planning and optimization, the work of service system must be managed in real time. Certainly, without service quality and productivity management models and systems, the mentioned measures are only the tools; therefore performance management models should be applied as well.

The goal of the research is to perform evaluation of self-service systems and to develop improvement model for increasing its profitability. Service system profitability increases when improves the quality of provided services and decrease supply costs. Due to insufficient level of their computerization, the developed method may be hardly applied for rendering traditional services. Therefore, more restricted area of service systems is analyzed in the paper - self-service facility systems - ATM networks.

The second section of the paper presents analysis of the literature concerning service systems productivity. The self-service systems performance evaluation model is described in the third section. The forecasting and optimization methods are described in the fourth section. According to presented evaluation model, fifth section provides detailed description of experimental results of ATM networks profitability simulation.

\section{Service Systems Productivity}

The concept of productivity in service area started to be analyzed only at the end of the XX century. Service sector is one of the fastest growing economy segments [4]; still only few empirical surveys have been conducted in productivity management area. Gronroosa [5], Chase and Haynes [6] structured the elements of service productivity theory. They analyzed the similarities and differences of production and service productivity, and formulated the main definitions of service productivity. Ojasalo [7] structured the model of service productivity. Sherman [8] defined service productivity components. Seth [1] carried out survey on quality management models, developed in the period of 1984-2003. It is obvious that service delivery process changes from traditional to the one reasoned by information technologies. Application of information technologies in service quality management is becoming highly important. Service sector productivity depends on technologies and process automation measures [9], at present this tendency is even more significant because the competition in service sector is increasing. Service delivery through self-service terminals or computer systems allows increasing the efficiency of service system and the quality of providing services. It is obvious that higher profitability is typical for efficiently operating systems [8].

Semeijn and others [10] showed that the work of servicing system is none the less important than the e-service system itself. Implementation of the best and most functional ATMs cannot ensure high level of self-service facilities without an appropriately functioning service system. Voss's [11] survey shows that service quality expectations in retail banking only approximately fulfill the service received. 
Problems, which appear in service systems, may disturb delivery process [12]; in most cases unavailable services greatly reduce the loyalty of a service [13]. For this reason it is important to combine internal and external quality criteria. Only one or another group of criteria is usually analyzed in literature, and a common model of self-service network quality is not provided.

Productivity evaluation system of e-services is discussed by Gronroos [5]; Ojasalo, [7]; Rutkauskas et al. [14]. Service productivity management is a very important topic, but very little empirical research has been carried out in this area [15]. Productivity consists of 4 components [8]: price, resource allocation, technological and scale efficiency. The main dilemma of productivity is balancing of revenue and costs [16]. Depending on demand, it is necessary to ensure efficient use of resources because services cannot be stored. Productivity is divided into internal and external. Internal productivity describes how efficiently resources are used. External productivity shows what service profitability is. Services productivity is the balance of external and internal efficiency [6]. Another important element of productivity is demand management or capacity efficiency, because supplier cannot store services [5]. Capacity efficiency shows how efficiently system internal resources satisfy the demand. The process of services is an open system therefore application of traditional efficiency evaluation systems may determine false results. Productivity may be evaluated totally or partially. According to Gronroos [5], the only theoretically and practically significant way to calculate services productivity is financial measures.

Internal quality of a system is ensured by using advanced management tools, that allow optimizing operational costs and service delivery process, and by using internal quality management systems, which are based on sets of productivity criteria. Clearly detailed productivity criteria of ATM network internal quality management systems are analyzed in articles of Aldlaigan and Buttle [17], Bahia and Nantel [18], Jabnoun and Al-Tamimi [19], Joseph and Stone [20]. In order to ensure external quality, process development measures and external quality management systems are necessary. External quality management systems were analyzed by Lovelock [21], Johnston and Clark [22], Edvardsson and others [23], they settled value-based service quality management models, which analyze economic and social service delivery aspects.

\section{Self-service Systems Performance Evaluation}

The main quality evaluation criteria of self-service systems were analyzed by Aldlaigan and Buttle [17], Bahia and Nantel [18], Jabnoun and Al-Tamimi [19], Joseph and Stone [20]. Most authors distinguish 5 criteria, which make the basics of ATM service quality: sufficient size of ATM network, safe environment, userfriendly connection, convenient allocation, and ATM functionality. Evaluation of service delivery should be carried out according to the criteria of e-service benefit/value: environmental features, security, communication speed, reliability, customer support, responsiveness, information completeness, availability, delivery and personalization [24].

The figure 1 shows the model of self-service system performance criteria; the model elaborates productivity components and sets out methodologies, which may be applied to ensure internal, external and capacity efficiency. It was found that internal 
productivity of self-service terminals may be increased by using cheaper maintenance resources if it does not have negative impact on quality, also by implementing more advanced technological decisions, and by optimal distribution of resources. Service resources may be optimized the way that their amount in self-service infrastructure would always satisfy the demand, therefore it is necessary to know what the demand will be, and forecast tools used for its determination. Knowing the demand, it is possible to foresee necessary amount of resources, and this is especially important in such service systems, where resources are of short validity or are realizable and can be used to earn income by another way.

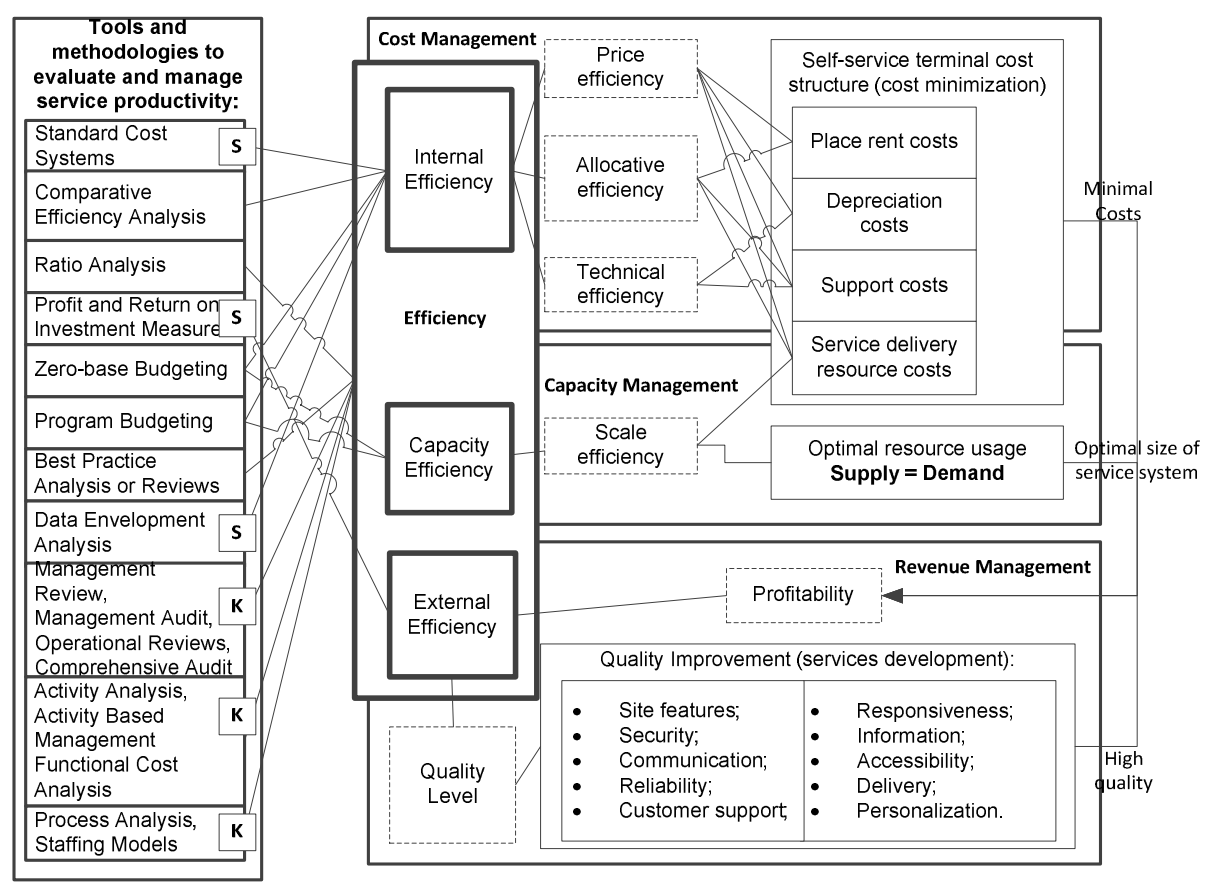

Fig. 1. Self-service system performance criteria model

Productivity is comprised of several components that independently influence the overall efficiency of the organization. The components are 1) price efficiency, 2) allocative efficiency, 3) technical efficiency, and 4) scale efficiency [8]. Price efficiency requires purchasing the inputs that meet the quality standard at the lowest price. Allocative efficiency is the use of the optimal mix of inputs to produce the products or services. Technical inefficiency exists when it is possible to produce more outputs with the inputs used or where it is possible to produce the actual outputs with fewer inputs. Scale efficiency is the component that addresses the optimal activity volume level, producing more or less goods or services than the optimal level results in added costs solely due to volume or size [8]. 
Different management tools and methodologies can be used to evaluate and manage service productivity. In model, these tools are classified by three categories: $\mathrm{K}$ - Qualitative, S - Quantitative and without marking both K/S.

The model line connecting the methodology and the performance component shows which technique is applicable to evaluate performance of specific component. The external productivity consists of profitability and quality evaluation criteria's.

\section{Self-service Systems Performance Assessment Model}

Productivity may be evaluated by physical, financial and combined measures; they may totally or partially evaluate productivity [7]. All productivity evaluation criteria may be derived from them (Table 1), in accordance with the self-service systems performance criteria model.

Table 1. Self-service systems productivity evaluation criteria's

\begin{tabular}{lccc}
\hline Evaluation criteria & Features $^{\text {I }}$ & Component $^{2}$ & Type $^{\mathbf{3}}$ \\
\hline $\begin{array}{l}\text { Maximum Capacity = work time / average } \\
\text { duration of one transaction }\end{array}$ & FIZ & MEF & DP \\
\hline $\begin{array}{l}\text { System Load = Number of transactions } \\
\text { performed / work time I maximum limitation } \\
\text { under the load condition }\end{array}$ & FIZ & MEF & DP \\
\hline $\begin{array}{l}\text { "Freeze" Resources = returned or lost resources / } \\
\text { all resources I rating per terminal }\end{array}$ & FIZ & MEF & DP \\
\hline $\begin{array}{l}\text { Availability = no working time / total hours } \\
\text { worked I rating per terminal }\end{array}$ & FIZ & TNAS & DP \\
\hline $\begin{array}{l}\text { Reliability = failed transactions / total } \\
\text { transactions I rating per terminal }\end{array}$ & FIZ & TNAS & DP \\
\hline $\begin{array}{l}\text { Total Maximum Load = (work time / average } \\
\text { time of one transactions) } * \text { number of terminals I } \\
\text { maximum limitation under the overall load } \\
\text { condition; }\end{array}$ & FIZ & MEF & PP \\
\hline $\begin{array}{l}\text { Total Load = number of transactions performed / } \\
\text { total amount of resources; }\end{array}$ & FIZ & MEF & PP \\
\hline $\begin{array}{l}\text { Total "Freeze" Resources = returned or lost } \\
\text { resources / all resources I rating for all terminals }\end{array}$ & FIZ & MEF & PP \\
\hline $\begin{array}{l}\text { Total Availability = no working time / total hours } \\
\text { worked I rating for all terminals }\end{array}$ & FIZ & TNAS & PP \\
\hline $\begin{array}{l}\text { Total Reliability = failed transactions / total } \\
\text { transactions I rating for all terminals }\end{array}$ & FIZ & TNAS & PP \\
\hline
\end{tabular}

\footnotetext{
${ }^{1}$ Features: FIZ - physical, FIN - financial, KOM - combined;

${ }^{2}$ Component: KNAS - Price efficiency; IPNAS - Allocative efficiency; TNAS - Technical efficiency ; MEF - Scale efficiency; PEL - Profitability;

${ }^{3}$ Type: PP - total productivity; DP - partially productivity;
} 
Table 1. (Continued)

\begin{tabular}{|c|c|c|c|}
\hline $\begin{array}{l}\text { Support Performance }=\text { [revenue of services }= \\
\text { (transaction price }+ \text { sold product) }] / \text { labor costs I } \\
\text { rating for all terminals; }\end{array}$ & FIN & KNAS & DP \\
\hline $\begin{array}{l}\text { Service delivery efficiency }=[\text { revenue of service } \\
=(\text { transaction price }+ \text { sold product })] / \text { all costs II } \\
\text { rating for all terminals; }\end{array}$ & FIN & KNAS & PP \\
\hline $\begin{array}{l}\text { Terminals Revenue Productivity }=\text { revenue of } \\
\text { services }=\text { (transaction price }+ \text { sold product }) / \\
\text { number of terminals }\end{array}$ & $\mathrm{KOM}$ & PEL & DP \\
\hline $\begin{array}{l}\text { Terminal Cost Efficiency }=\text { number of } \\
\text { transactions performed / resource costs }\end{array}$ & $\mathrm{KOM}$ & IPNAS & $\mathrm{PP}$ \\
\hline $\begin{array}{l}\text { Productivity = number of transactions or sold } \\
\text { product units / (outsourcing, depreciation, } \\
\text { maintenance, support or services delivery costs) }\end{array}$ & $\mathrm{KOM}$ & KNAS & DP \\
\hline
\end{tabular}

DEA analysis [8] is most suitable for evaluation of internal performance of selfservice systems.

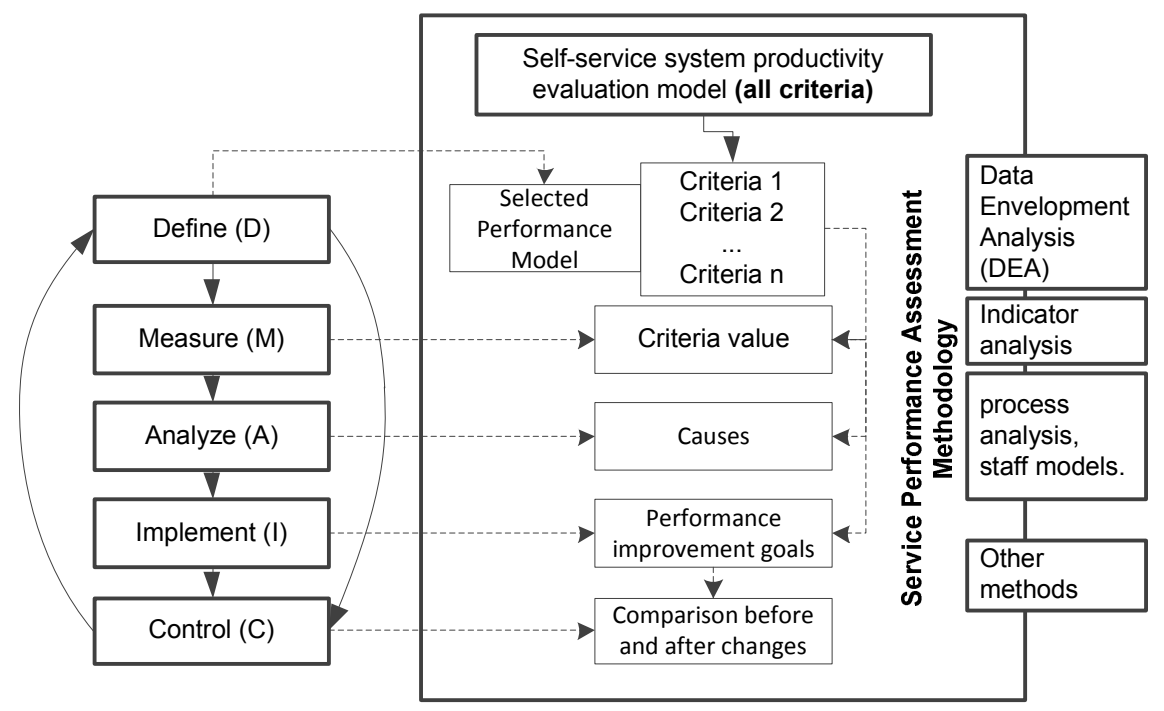

Fig. 2. The model of self-service system performance assessment

Electronic services quality model is applied for the evaluation of external performance of self-service systems [25]. This model provides full set of criteria for the assessment of service content and functionality. IT-based model [26], which assesses IT importance for the delivery of services, is applied for evaluation of social aspects: age, mood for using e-services.

The figure 2 presents self-service system performance model. Self-service system performance assessment model needs to be formulated in accordance with the criteria, 
formulated in the table 1 . First the calculations are prepared and then the most appropriate evaluation criteria are selected. Following this, the productivity model is developed and simulations consisting real data are done. The obtained results are evaluated by comparing the results between ATM's. After analysis of the results, the reasons for low productivity are identified. Eventually tools have to be prepared to eliminate the causes of low productivity. The goals are set for performance improvement. After the changes and improvement are made, the comparison has to be done, in order to evaluate whether the realized changes increased productivity.

\section{$4 \quad$ Profitability Simulation}

This section describes experimental results of ATM network profitability analysis, using proposed performance evaluation methods and models.

\subsection{Artificial Neural Network Model of Demand Forecasting}

A flexible neural network model has been created, which changes its structure depending on situation and is used to forecast self-service facility demand. Considering the forecast results, the optimization procedure foresees optimal resource loads of ATM network.

In our past researches we have already presented experimental research of ANN model [27]. We came to the conclusion, that the best forecasting results are reached using direct spread multilayer neural network with one hidden layer, consisting of fifteen neurons in the hidden layer (transfer function - hyperbolic tangent) and one output (linear neuron), chosen for ATM cash prediction. Neural network has 6 inputs: average cash demand of the last 7 days, day of the week, month of the year, day of the month, days before holidays and time series record number. The output is ATM cash demand forecast for the following day or week if week discretion data is transferred.

Flexibility of neural network is controlled by limiting the weight of neural networks. For this reason, additional member D is introduced into the neural network prediction error expression, which punishes the network for high weight values (i.e. too high flexibility).

\subsection{ATM Network Optimization of Resource Delivery}

ATM network optimization topics include three areas: selection of optimal ATM network size [29], cash demand specifics (size of cash on the market) [30-33], and forecast of cash flow demand in ATM networks [27,28]. Analysis of applied methods showed that most frequently analyzed economic models (dependencies) influence cash market structure by factors. Real decisions and tools, which could help to optimize ATM cash management, are not provided.

For profitability modeling we are using ATM optimization function to model such amounts of cash load, which minimize ATM operation expenses. Optimization is performed in consideration of interest rate, upload costs, forecast recommendations 
and cash management limitations: cash balance, cash insurance expenses, maximum amount of cash, minimal amount of cash, possible ATM unavailability period. Output of optimization function is the date of cash upload into ATM and optimal cash amount, which is necessary to upload in an ATM in order to minimize ATM operation expenses.

ATM cash management costs $=$ Cash $*$ Interest + Cash $*$ Insurance $+($ RUC or EUC) + Penalty $\rightarrow$ minimize, where

Cash - ATM cash amount (limitations: possible minimum and maximum load); Interest - interest rate, \%; Insurance - insurance rate, \%; RUC - Regular upload costs; EUC - Extra upload costs; Penalty - penalty if ATM is not accessible more than $2 \%$ of all working time.

\subsection{ATM Networks Profitability Simulation}

Experimental research of 2 types has been carried out in the paper: low load and high load ATM network profitability simulation. High load ATM networks are replenished more than one time per day, via versa low load. For high load ATM network simulation we used India bank data of 5500 ATMs (duration up to 3 months). For low load ATM network simulation we used data of Lithuanian bank of 21 ATM (duration - 6 months). In both cases we evaluated optimal (when ANN method is used) and typical (real bank process) models.

After modeling high load ATM network productivity, we found that average productivity of ANN model for a group of accurate ATMs is $17.73 \%$ (assessing losses $11.16 \%$ ). Optimal model, compared to a typical one is $18 \%$ more productive. This criterion characterizes capacity productivity component and shows how productively the existing resources may be used. It is attributable to financial productivity criteria, and only partially evaluates productivity. The amounts of cashback are decreased by $90 \%$. This criterion shows the productivity of resource distribution.

ATM model average productivity for a group of average ATMs is $26.27 \%$ (assessing losses 12.18\%), amounts of cash-back are decreased by $32.2 \%$ (assessing loss $11.16 \%$ ), and the amounts of cash-back are reduced by $653 \%$. Benefit without loss is the highest in the group of inaccurate ATMs, its increase is determined by obvious facts, i.e., bigger amounts of cash are uploaded in hardly forecasted ATMs, because standard deviation is much higher than in the case of accurate and average group models.

In regard to accurate ATM group, a network of 5000 ATMs can save 4250 Euros per day, and if the free cash is lent, 2660 Euros may be earned. Total saving and profit benefit would reach 6900 Euros per day, what would allow making 2.52 million Euro profit per year. Average profit of all model groups is 2.35 million Euros per year. Cash management costs are approximately reduced by $25 \%$.

After modeling low load ATM network productivity (detailed evaluation results are presented in Tables 2 and 3), we found that in optimal case average cash-back amounted $13.15 \%$; in typical case $-37.23 \%$. 
Table 2. ATM network management efficiency modeling results of the Lithuania Bank (Optimal Model)

\begin{tabular}{|c|c|c|c|c|c|}
\hline \multicolumn{6}{|c|}{ Optimal model (using ANN forecasting and optimization procedures) } \\
\hline ATM number & ATM5011 & ATM1004 & ATM1045 & ATM2001 & ATM7012 \\
\hline From & $2009-5$ & $2009-2$ & $2009-3$ & $2009-5$ & $2009-5$ \\
\hline Till & $2010-2$ & 2009-11 & $2010-2$ & $2010-2$ & $2010-2$ \\
\hline Average load & 73928 & 58752 & 35732 & 36574 & 39695 \\
\hline Average Cash back & 4225 & 5462 & 8277 & 3687 & 6938 \\
\hline Cash Back \% & $5.71 \%$ & $9.30 \%$ & $23.17 \%$ & $10.08 \%$ & $17.48 \%$ \\
\hline Cash Load Quantity & 50 & 46 & 36 & 35 & 31 \\
\hline $\begin{array}{l}\text { Cash Price (interest from } \\
\text { cash back) }\end{array}$ & 244 & 400 & 723 & 281 & 460 \\
\hline Cash Load Price & 1225 & 1125 & 875 & 850 & 750 \\
\hline Total Cash Price (CB) & 1469 & 1525 & 1598 & 1131 & 1210 \\
\hline Frozen Cash (interest) & 1469 & 2188 & 1709 & 1457 & 1264 \\
\hline Total Cash Price (UZ) & 3409 & 3313 & 2584 & 2307 & 2014 \\
\hline Efficiency $(\mathrm{CB})$ & $47.11 \%$ & $59.77 \%$ & $-2.51 \%$ & $68.88 \%$ & $28.80 \%$ \\
\hline Efficiency (UZ) & $44.75 \%$ & $28.20 \%$ & $28.36 \%$ & $45.90 \%$ & $15.18 \%$ \\
\hline
\end{tabular}

Table 3. ATM network management efficiency modeling results of the Lithuania Bank (Typical Model)

\begin{tabular}{lccccc}
\hline \multicolumn{7}{c}{ Typical model (typical bank scenario) } \\
\hline ATM number & ATM5011 & ATM1004 & ATM1045 & ATM2001 & ATM7012 \\
\hline From & $2009-5$ & $2009-2$ & $2009-3$ & $2009-5$ & $2009-5$ \\
\hline Till & $2010-2$ & $2009-11$ & $2010-3$ & $2010-2$ & $2010-2$ \\
\hline Average load & 147616 & 88533 & 58685 & 46321 & 41401 \\
\hline Average Cash back & 27505 & 49540 & 14313 & 26190 & 12686 \\
\hline Cash Back \% & $18.63 \%$ & $55.96 \%$ & $24.39 \%$ & $56.54 \%$ & $30.64 \%$ \\
\hline Cash Load Quantity & 38 & 49 & 23 & 59 & 34 \\
\hline $\begin{array}{l}\text { Cash Price (interest } \\
\text { from cash back) }\end{array}$ & 1827 & 2566 & 984 & 2158 & 850 \\
\hline Cash Load Price & 950 & 1225 & 575 & 1475 & 850 \\
\hline Total Cash Price (CB) & 2777 & 3791 & 1559 & 3633 & 1700 \\
\hline Frozen Cash (interest) & 5220 & 3390 & 3031 & 2789 & 1525 \\
\hline Total Cash Price (UZ) & 6170 & 4615 & 3606 & 4264 & 2375 \\
\hline
\end{tabular}

Using the created ATM network cash management model, the amounts of cashback were decreased by $24.08 \%$, compared to a real scenario. Model efficiency shows that using the created ANN method and optimization procedure, the cash supply productivity of certain ATMs may be increased by $44.75 \%$ (ATM5011), $45.90 \%$ (ATM2001). 
Figure 3 presents graphic generalization of modeling results of ATM No 5011; we notice that in case of optimal scenario, cash collecting is balanced in respect of cash demand. Using the created ANN method and optimization procedure, cash supply productivity of ATM5011 is increased by 44.75\% (ATM5011), compared to the model, applied in a bank.

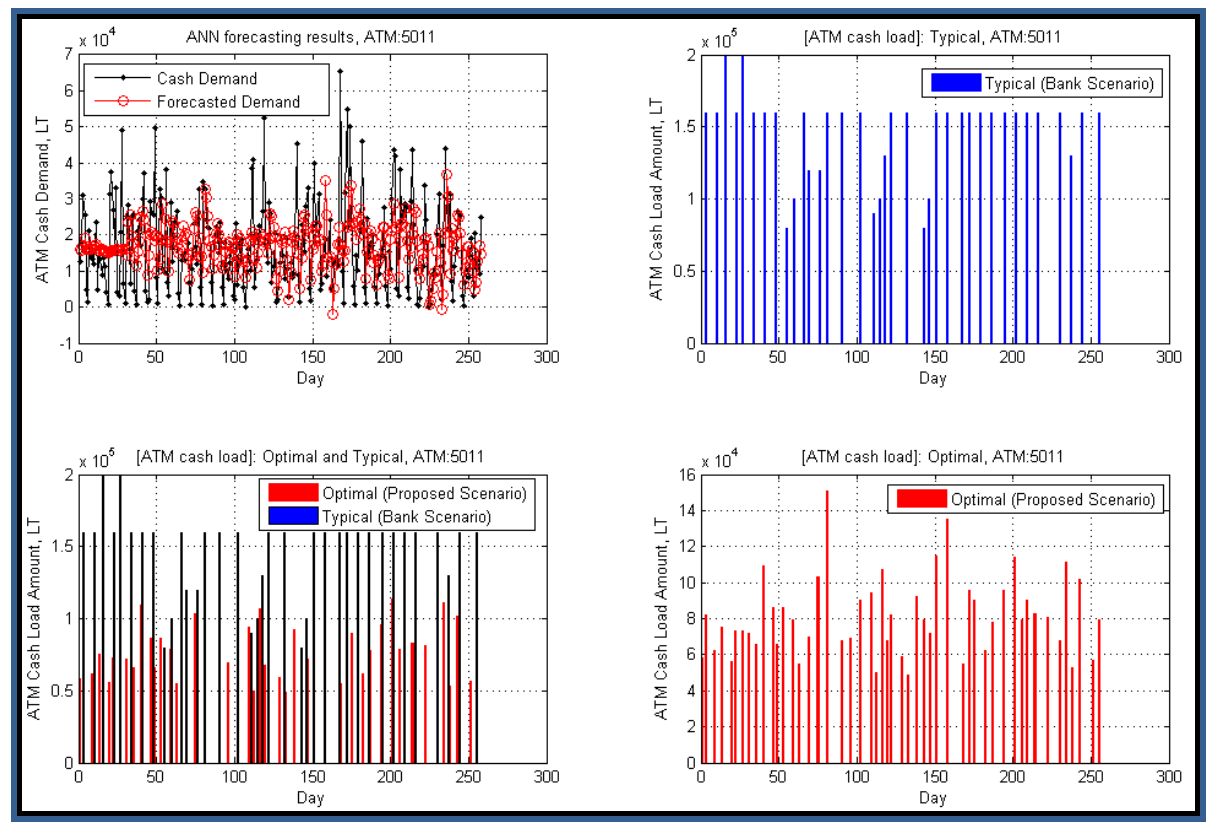

Fig. 3. Cash load model of ATM5011

Using the created ATM network cash management model for low load ATM network management, the cash-back amounts are reduced by approximately $24 \%$, compared to a real scenario. Using the created ANN method and optimization procedure, ATM cash management performance may be approximately increased by $33 \%$.

\section{Conclusions}

The productivity of electronic services may be ensured by implementing advanced real-time decision management systems, i.e., changing the realization of service system quality from traditional to predictive. Application of information technologies in service quality management is becoming highly important.

The work of service system must be managed in real time, applying intelligent systems of resource planning and optimization. Certainly, without service quality, productivity management models and systems, the advance software is only a tool; therefore performance management models should be applied as well. 
It was found that internal productivity of self-service terminals may be increased by using cheaper maintenance resources, by implementing more advanced technological decisions, and, by optimal distribution of resources. More productive distribution of resources may be performed using accurate service demand forecast measures.

Analysis of high and low load ATM network profitability showed that proposed self-service systems performance evaluation and improvement methods allow decreasing the amounts of cash-back by $24 \%$ and increasing cash management productivity up to $33 \%$.

\section{References}

1. Seth, N., Deshmukh, S.G., Vrat, P.: Service quality models: a review. International Journal of Quality \& Reliability Management 22(9), 913-949 (2005)

2. Gartner: Emerging Technologies Will Help Drive Mainstream BI Adoption (2008), http: / / www.gartner.com/

3. Dilijonas, D., Bastina, L.: Retail banking optimization system based on multi-agents technology. In: 16th WSEAS International Conference on Computational Intelligence, Man-Machine Systems and Cybernetics, December 14-16, pp. 204-209 (2007)

4. Sahay, B.S.: Multi-factor productivity measurement model for service organization. International Journal of Productivity and Performance Management 2(1), 7-22 (2005)

5. Gronroos, C., Ojasalob, K.: Service productivity Towards a conceptualization of the transformation of inputs into economic results in services. Journal of Business Research 57, 414-423 (2004)

6. Chase, R.B., Haynes, R.M.: Service operations management. A field guide. In: Swartz, T.A., Iacobucci, D. (eds.) Handbook of Services Marketing and Management, pp. 455-472. Sage Publications, Thousand Oaks (2000)

7. Ojasalo, K.: Conceptualizing productivity in services. Hanken Swedish School of Economics Finland/CERS Center for Relationship Marketing and Service Management. Helsinki/Helsingfors (1999)

8. Sherman, H.D., Zhu, J.: Service Productivity Management, Improving Service Performance using Data Envelopment Analysis (DEA), pp. 2-5. Springer, Heidelberg (2006)

9. Gummesson, E.: Productivity, quality and relationship marketing in service operations. International Journal of Contemporary Hospitality Management 10(1), 4-15 (1998)

10. Semeijn, J., Van Riel, A.C.R., Birgelen, M.J.H., Streukens, S.: E-services and offline fulfillment: how e-loyalty is created. Managing Service Quality 15(2), 182-194 (2005)

11. Voss, C.A.: Rethinking paradigms of service - service in a virtual environment. International Journal of Operations \& Production Management 23(1), 88-105 (2003)

12. Zhang, X., Prybutok, V.R.: A consumer perspective of e-service quality. IEEE Transactions on Engineering Management 52(4), 461-477 (2005)

13. Watcher, K.: Longitudinal assessment of web retailers: issues form a consumer point of view. Journal of Fashion Marketing and Management 18(1), 53-69 (2002)

14. Rutkauskas, J., Paulaviciene, E.: Concept of Productivity in Service Sector. Engineering Economics 3(43), 29-34 (2005); Influence of quality management of the country's economy, ISSN 1392-2785 
15. Johnston, R.: Service productivity: Towards understanding the relationship between operational and customer productivity / R. Johnston, P. Jones. International Journal of Productivity and Performance Management 53(3), 201-213 (2004)

16. Gronroos: Service management and marketing. A customer relationship management approach. Wiley, Chichester (2000)

17. Aldlaigan, A., Buttle, A.: SYSTRA-SQ: a new measure of banks service quality. International Journal of Service Industry Management 13(4), 362-381 (2002)

18. Bahia, K., Nantel, J.: A reliable and valid measurement scale for the perceived service quality of banks. The International Journal of Bank Marketing 18(2), 84-91 (2000)

19. Jabnoun, N., Al-Tamimi, H.A.: Measuring perceived service quality at UAE commercial banks. International Journal of Quality \& Reliability Management 20(4), 458-472 (2003)

20. Joseph, M., Stone, G.: An empirical evaluation of US bank customer perceptions of the impact of technology in service delivery in the banking sector. International Journal of Retail \& Distribution Management 31(4), 190-202 (2003)

21. Lovelock, C.H.: Functional integration in service: understanding the links between marketing, operations, and human resources. In: Swartz, T.A., Iacobucci, D. (eds.) Handbook of Marketing and Management. Sage, Thousand Oaks (2000)

22. Johnston, R., Clark, G.: Service Operations Management. Prentice Hall, London (2001)

23. Edvardsson, B., Enquist, B., Hay, M.: Values based service brands: narratives from IKEA. Managing Service Quality 16(3), 230-246 (2006)

24. Rowley, J.: An analysis of the e-service literature: towards a research agenda. Internet Research 16(3), 339-359 (2006)

25. Santos, J.: E-service quality: a model of virtual service quality dimensions. Managing Service Quality 13(3), 233-246 (2003)

26. Zhu, F.X., Wymer, W.J., Chen, I.: IT-based services and service quality in consumer banking. International Journal of Service Industry Management 13(1), 69-90 (2002)

27. Simutis, R., Dilijonas, D., Bastina, L.: Cash demand forecasting for ATM using neural networks and support vector regression algorithms. In: Continuous Optimization and Knowledge-Based Technologies, 20th EURO Mini Conference, May 20-23, pp. 416-421 (2008)

28. Sakalauskas, V., Dilijonas, D., Kriksciuniene, D., Simutis, R.: Intelligent systems for retail banking optimization-Optimization and Management of ATM Network System. In: ICEIS 2009 - 11th International Conference on Enterprise Information Systems, Milan, vol. AIDSS, pp. 321-325 (2009)

29. McAndrews, J., Rob, R.: Shared ownership and pricing in a network switch. International Journal of Industrial Organization 14, 727-745 (1996)

30. Boeschoten, W.: Cash management, payment patterns and the demand for money. De Economist 146(1), 117-142 (1998)

31. Viren, M.: Financial innovations and currency demand, some new evidence. Empirical Economics, 451-461 (1992)

32. Snellman, H., Viren, M.: ATM Networks and Cash Usage. Fore presentation at the FMG/Cass Business School Workshop on Financial Regulation and Payment Systems at the Cass Business School on September 28 (2006)

33. Stix, H.: How do debit cards affect cash demand? Working Paper 82, Oesterreichische National bank (2003) 